\title{
Effects of Dietary Energy Density in the Dry Period on the Production Performance and Metabolism of Dairy Cows
}

\author{
Yun Wang*, Qiuling Hou*, Gaozhan Cai, Zhiyong Hu, Kerong Shi, Zhengui Yan, Xueyan Lin\#, \\ Zhonghua Wang ${ }^{\dagger}$
}

College of Animal Science, Shandong Agricultural University, Taian, China

Email: "linxueyan@sdau.edu.cn, ${ }^{\dagger}$ zhwang@sdau.edu.cn

How to cite this paper: Wang, Y., Hou, Q.L., Cai, G.Z., Hu, Z.Y., Shi, K.R., Yan, Z.G., Lin, X.Y. and Wang, Z.H. (2017) Effects of Dietary Energy Density in the Dry Period on the Production Performance and Metabolism of Dairy Cows. Advances in Bioscience and Biotechnology, 8, 104126

https://doi.org/10.4236/abb.2017.83008

Received: February 5, 2017

Accepted: March 24, 2017

Published: March 28, 2017

Copyright $\odot 2017$ by authors and Scientific Research Publishing Inc. This work is licensed under the Creative Commons Attribution International License (CC BY 4.0).

http://creativecommons.org/licenses/by/4.0/

\begin{abstract}
Thirty healthy Holstein dairy cows in the dry period were randomly divided into three groups and fed diets with different net energy for lactation (group A: $1.2 \mathrm{Mcal} / \mathrm{kg}$ DM, group B: $1.3 \mathrm{Mcal} / \mathrm{kg} \mathrm{DM}$, and group C: $1.4 \mathrm{Mcal} / \mathrm{kg} \mathrm{DM}$ ) for 8 weeks prepartum. Thereafter, dairy cows were fed a diet of the same formulation ( $1.66 \mathrm{Mcal} / \mathrm{kg} \mathrm{DM})$ for 12 weeks postpartum. The effects of different dietary energy densities in the dry period on postpartum performance and metabolic parameters of dairy cows were observed. Milk yield was reduced by $14.5 \%$ in the low-energy diet group; however, there were no differences in milk composition between the three groups. Postpartum plasma $\beta$-hydroxybutyrate, non-esterified fatty acid, growth hormone, and glucagon levels were significantly decreased whereas leptin and neuropeptide levels were elevated in the low-energy diet group. Moreover, body fat mobilization was attenuated, and the decline in postpartum body condition was reduced in the low-energy diet group, thus effectively reducing the postpartum negative energy balance.
\end{abstract}

\section{Keywords}

Dry Period, Dairy Cows, Energy, Production Performance, Biochemical Indicator, Hormone Level

\section{Introduction}

The greatest metabolic characteristic of dairy cows in early lactation is negative energy balance (NEB) due to insufficient energy intake that fails to meet the needs. Prolonged postpartum NEB contributes to a high incidence of postpar-

*Yun Wang and Qiuling Hou have equal contribution to this article. 
tum metabolic diseases (fatty liver and ketosis). Increasing prepartum dietary energy density (DED) is commonly used to reduce the NEB; however, this approach often increases the incidence of postpartum metabolic diseases [1]. Grummer found that increasing prepartum dry matter intake (DMI) can reduce the NEB [2]. In recent years, increasing research has demonstrated that limited feeding in the dry period may have a better effect [3] [4] [5] [6].

Recent research has primarily focused on dietary nutrition in the early peripartum period (3 - 4 weeks prepartum); however, the entire dry period was overlooked. Evidence indicates that low-energy feeding for 60 - 30 days prepartum can increase postpartum DMI, reduced the NEB, attenuate body fat mobilization, and markedly decrease blood NEFA and BHBA levels of dairy cows [6] [7]. Beever reported that one-stage feeding (using diets with the same energy density throughout the dry period) improved the health and reproductive performance of cows on dozens of dairy farms in France, Britain, and Ireland [8]. However, there is a lack of specific research data as supporting evidence. In the present study, we fed dairy cows diets of different energy densities in the dry period and observed their effects on postpartum production and metabolism to establish a new feeding pattern and appropriate energy density. This study lays the foundation and provides a theoretical basis to correct and reduce the postpartum $\mathrm{NEB}$, improve the postpartum performance, and reveal the mechanism of metabolic diseases in dairy cows.

\section{Materials and Methods}

\subsection{Cow Selection, Grouping and Feeding}

An animal feeding trial was conducted from July 2014 through January 2015 on the dairy farm of Shandong Expressway Modern Husbandry Co., Ltd. (Jiyang, Shandong Province, China). Thirty healthy Holstein dairy cows were selected with consistent age, parity ( $2.5 \pm 0.57)$, and body condition ( $3.17 \pm 0.14), 305$ days milk yield is more than $7000 \mathrm{~kg}(27.46 \pm 1.72 \mathrm{~kg}$ everyday) The animals were randomly divided into three groups and fed diets of different net energies for lactation $\left(\mathrm{NE}_{\mathrm{L}}\right.$; group $\mathrm{A}: 1.2 \mathrm{Mcal} / \mathrm{kg} \mathrm{DM}$, group $\mathrm{B}: 1.3 \mathrm{Mcal} / \mathrm{kg} \mathrm{DM}$, and group C: $1.4 \mathrm{Mcal} / \mathrm{kg} \mathrm{DM}$ ) for 8 weeks prepartum. Thereafter, the animals were changed to a diet of the same formulation for 12 weeks postpartum. The general condition of the three groups is shown in Table 1. The formulation and nutrient composition of diets are summarized in Table 2.

Table 1. General condition of the three groups of experimental cows.

\begin{tabular}{|c|c|c|c|c|c|}
\hline & \multicolumn{3}{|c|}{ Group } & \multirow{2}{*}{ SEM } & \multirow{2}{*}{$P$} \\
\hline & A & B & $\mathrm{C}$ & & \\
\hline$n^{1}$ & 10 & 10 & 10 & & \\
\hline Parities & 2.6 & 2.6 & 2.3 & 0.10 & 0.41 \\
\hline Daily milk yield ${ }^{2}, \mathrm{~kg} / \mathrm{d}$ & 25.9 & 25.5 & 26.2 & 0.33 & 0.68 \\
\hline Body condition score & 3.17 & 3.18 & 3.17 & 0.03 & 0.98 \\
\hline
\end{tabular}

${ }^{1}$ Multiparous Holstein cows with averaging $762 \pm 58 \mathrm{~kg}$ of BW. ${ }^{2}$ calculated by milk yield in 305 days. 
Table 2. Formulation and nutrient composition of experimental diets (\% dry matter).

\begin{tabular}{|c|c|c|c|c|}
\hline Item & Diet A & Diet B & Diet C & Postpartum diet \\
\hline Alfalfa & 0 & 0 & 0 & 8.25 \\
\hline Leymus & 25.76 & 26.38 & 22.90 & 8.31 \\
\hline Silage & 0 & 0 & 0 & 18.64 \\
\hline Yellow corn silage & 31.51 & 32.28 & 28.01 & 0 \\
\hline Jujube & 15.48 & 6.06 & 5.25 & 0 \\
\hline Bran & 4.90 & 5.01 & 4.35 & 5.96 \\
\hline Soybean meal & 12.20 & 11.68 & 11.32 & 12.78 \\
\hline Corn & 8.53 & 16.92 & 26.72 & 38.91 \\
\hline Vinasse & 0 & 0 & 0 & 5.81 \\
\hline Premix $^{*_{1}}$ & 1.63 & 1.67 & 1.45 & 1.34 \\
\hline Concentrate: Forage & $43: 57$ & $41: 59$ & 49:51 & $59: 41$ \\
\hline \multicolumn{5}{|c|}{ Nutrient composition } \\
\hline Organic matter (\%) & 90.90 & 92.27 & 93.04 & 94.69 \\
\hline Crude fat (\%) & 1.74 & 1.96 & 2.17 & 3.36 \\
\hline Crude protein ${ }^{* 1}(\%)$ & 12.12 & 12.09 & 11.95 & 15.08 \\
\hline Acid detergent fiber ${ }^{* 1}(\%)$ & 34.33 & 31.11 & 27.37 & 17.37 \\
\hline Neutral detergent fiber ${ }^{*_{1}}(\%)$ & 55.30 & 52.01 & 46.70 & 32.14 \\
\hline Net energy for lactation ${ }^{* 2}\left(\mathrm{NE}_{\mathrm{L}}\right)(\mathrm{Mcal} / \mathrm{kg})$ & 1.21 & 1.30 & 1.39 & 1.66 \\
\hline
\end{tabular}

Note: ${ }^{*}$ Premix (VA: $200 \mathrm{KIU} / \mathrm{kg}, \mathrm{VD}_{3}: 10.4 \mathrm{KIU} / \mathrm{kg}$, VE: $1200 \mathrm{IU} / \mathrm{kg}$, P: $32000 \mathrm{mg} / \mathrm{kg}, \mathrm{Mn} ; 1850 \mathrm{mg} / \mathrm{kg}, \mathrm{Zn}$ : $3900 \mathrm{mg} / \mathrm{kg}$, Ca: $202000 \mathrm{mg} / \mathrm{kg}$, Cu: $500 \mathrm{mg} / \mathrm{kg}$, Fe: $3600 \mathrm{mg} / \mathrm{kg}$, S: $22000 \mathrm{mg} / \mathrm{kg}$, Se: $15 \mathrm{mg} / \mathrm{kg}$, Co: 20 $\mathrm{mg} / \mathrm{kg}) .{ }^{{ }^{2}} \mathrm{NE}_{\mathrm{L}}=\mathrm{Net}$ energy for lactation; this parameter is calculated as follows; other parameters are measured values. $\mathrm{NE}_{\mathrm{L}}(\mathrm{Mcal} / \mathrm{kg} \mathrm{DM})=0.5501 \times$ dietary energy $(\mathrm{Mcal} / \mathrm{kg} \mathrm{DM})-0.0946(r=0.9172)$.

The animals were prefed for 1 week, with stall feeding, free activity, and consistent living environment. The animals were subsequently given ad libitum access to food and water during the trial period. A total mixed ration diet was applied twice a day at 8:30 am and 2:30 pm prepartum and at 7:00 am and 1:30 pm postpartum. Pipeline milking was performed three times a day, at 7:00 am, 1:30 pm, and 8:00 pm. The remaining feed was removed every day and controlled within $10 \%$.

\subsection{Major Equipment, Sample Collection and Parameter Analysis}

Major equipment: Low-speed desktop centrifuge, high-speed refrigerated centrifuge, electric blast drying oven, automatic Kjeldahl analyzer, automatic biochemical analyzer (Model 7020, Hitachi, Japan), $-20^{\circ} \mathrm{C}$ low-temperature refrigerator, semi-automatic oxygen bomb calorimeter (Model 6200, PARR, USA), milk composition analyzer (Model: 78110, Flowserve, USA) and insulation box.

DMI determination: DMI was determined once a week from the start of the trial. The feed provided and remaining feed were weighed and recorded during each determination. Meanwhile, the original and remaining feed samples were collected to measure nutritional values, and the results were used to calculate DMI. 
Body condition scoring: Body condition score (BCS) was recorded once every two weeks from the beginning of the trial. Following the procedure of Ferguson et al. [9], three individuals performed the scoring each time, and the average of three scores was taken as the final BCS of the cow examined.

Milk yield and composition analysis: Daily milk yield (MY) was recorded to calculate the average daily MY per week.

Blood collection: Blood samples were analyzed once every 2 weeks prepartum. Moreover, blood samples were collected at the day of parturition (calving) and 7 , $14,28,42,56,70$, and 84 days postpartum. Venous blood samples were taken from the tail head using a sterile blood collector before the morning feeding. The samples were collected into $10-\mathrm{ml}$ centrifuge tubes containing heparin sodium and centrifuged at $3000 \mathrm{r} / \mathrm{min}$ for $15 \mathrm{~min}$. The supernatants were dispensed into $1.5-\mathrm{ml}$ centrifuge tubes, and the plasma was frozen at $-20^{\circ} \mathrm{C}$ until used.

Plasma biochemical tests: Plasma glucose (GLU), urea nitrogen (UREA), total protein (TP), albumin (ALB), alanine aminotransferase (ALT), and aspartate aminotransferase (AST) were measured using an automatic biochemical analyzer (Hitachi 7020) and a commercial kit (Maker Biotechnology Co., Ltd, Chengdu, China). Triglyceride (TG) and non-esterified fatty acid (NEFA) were assayed using commercial kits provided by Nanjing Jiancheng Bioengineering Institute (Nanjing, China). $\beta$-Hydroxybutyrate (BHBA) was analyzed using a bovine (cow) hormone ELISA kit purchased from Nanjing Jiancheng Bioengineering Institute. Insulin (INS), glucagon (GN), insulin-like growth factor-1 (IGF-1), and growth hormone $(\mathrm{GH})$ were measured by radioimmunoassay at the Central Hospital of Taian (Taian, China). GN and IGF-1 radioimmunoassay kits were purchased from Jiuding Medical and Biological Engineering Co., Ltd. (Tianjin, China); a GH radioimmunoassay kit was provided by North Institute of Biological Technology (Beijing, China); and an INS radioimmunoassay kit was obtained from Weifang 3V Bioengineering Group Co., Ltd (Weifang, China). Leptin (LEP) and neuropeptide (NPY) were analyzed using a bovine (cow) hormone ELISA kit purchased from Nanjing Jiancheng Bioengineering Institute. Formulation and nutrient composition of experimental diets (\% dry matter) (Table 2).

\subsection{Statistical Analysis}

A single-factor, completely randomized experimental design was used in this study. One-way analysis of variance was performed using SAS 8.2 statistical software (SAS Institute Inc., Cary, NC, USA). Multiple comparisons were made using Duncan's multiple range tests. $P<0.05$ indicates significant differences between groups; $P<0.01$ indicates highly significant differences between groups; and $0.05<P<0.1$ indicates a trend of difference.

\section{Results}

\subsection{Effects of DED in the Dry Period on Prepartum DMI of Dairy Cows}

Table 3 and Figure 1 demonstrate that the average daily DMI of dairy cows 
Table 3. Effects of dietary energy density in the dry period on the production performance of dairy cows.

\begin{tabular}{lccccc}
\hline \multicolumn{1}{c}{ Item } & Group A & Group B & Group C & SEM & P-value \\
\hline Dry matter intake (prepartum) (kg/d) & $11.96^{\mathrm{c}}$ & $13.41^{\mathrm{b}}$ & $14.31^{\mathrm{a}}$ & 0.42 & 0.0001 \\
Mild yield (kg/d) & $22.63^{\mathrm{b}}$ & $26.10^{\mathrm{a}}$ & $26.47^{\mathrm{a}}$ & 0.81 & $<0.0001$ \\
Fat (\%) & 4.19 & 4.16 & 4.01 & 0.12 & 0.1374 \\
Protein (\%) & 3.09 & 3.01 & 3.01 & 0.07 & 0.1554 \\
Lactose (\%) & 4.52 & 4.48 & 4.47 & 0.02 & 0.4740 \\
Non-fat solids (\%) & 8.61 & 8.80 & 8.73 & 0.18 & 0.2663 \\
Total solids (\%) & 12.38 & 12.11 & 12.55 & 0.15 & 0.1753 \\
Fat yield (g/d) & $891.01^{\mathrm{b}}$ & $911.37^{\mathrm{b}}$ & $1021.20^{\mathrm{a}}$ & 34.85 & 0.0171 \\
Protein yield (g/d) & $649.63^{\mathrm{b}}$ & $735.00^{\mathrm{a}}$ & $741.79^{\mathrm{a}}$ & 28.93 & $<0.0001$ \\
Lactose yield (g/d) & $968.48^{\mathrm{b}}$ & $1107.84^{\mathrm{a}}$ & $1104.23^{\mathrm{a}}$ & 54.76 & $<0.0001$ \\
\hline
\end{tabular}

Note: 1. Group A - low-energy diet $\left(\mathrm{NE}_{\mathrm{L}}=1.21 \mathrm{Mcal} / \mathrm{kg} \mathrm{DM}\right) ;$ Group B - medium-energy diet $\left(\mathrm{NE}_{\mathrm{L}}=1.30\right.$ $\mathrm{Mcal} / \mathrm{kg} \mathrm{DM})$; Group $\mathrm{C}-$ high-energy diet $\left(\mathrm{NE}_{\mathrm{L}}=1.39 \mathrm{Mcal} / \mathrm{kg} \mathrm{DM}\right)$. 2. For data within a row, different superscript letters indicate significant differences $(P<0.05)$, and the same superscript letters indicate no significant differences $(P>0.05) ; 0.05<P<0.1$ indicates a trend of difference; and $P>0.1$ indicates no significant difference. The same statistical rules apply to the following tables.

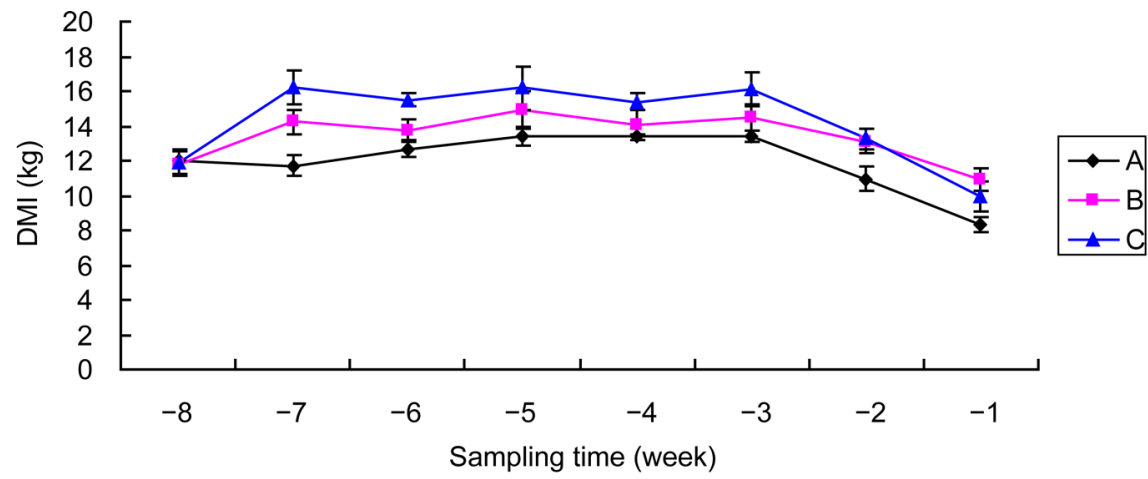

Figure 1. Effects of dietary energy density in the dry period on the prepartum dry matter intake (DMI) of dairy cows.

exhibited a decreasing trend from 3 weeks prepartum to calving in all groups, and the relative decreases were $38 \%, 24 \%$, and $39 \%$ in groups $\mathrm{A}, \mathrm{B}$, and C, respectively. For 8 weeks prepartum, group A was lower than group B, whereas group B was lower than group C. The average DMI values were 11.96, 13.41, and $14.31 \mathrm{~kg}$. There were highly significant differences among the three groups $(P<$ $0.01)$.

\subsection{Effects of DED in the Dry Period on MY and MC of Dairy Cows}

Table 3 and Figure 2 illustrate that the MY of dairy cows exhibited an upward trend for 1 - 6 weeks postpartum and then leveled off. Group A was highly significantly lower than groups $\mathrm{B}$ and $\mathrm{C}(P<0.01)$; the latter two exhibited no difference between each other. The decrease in MY was $14.5 \%$ for group A. Comparisons of group means revealed no difference in the content of milk fat, 

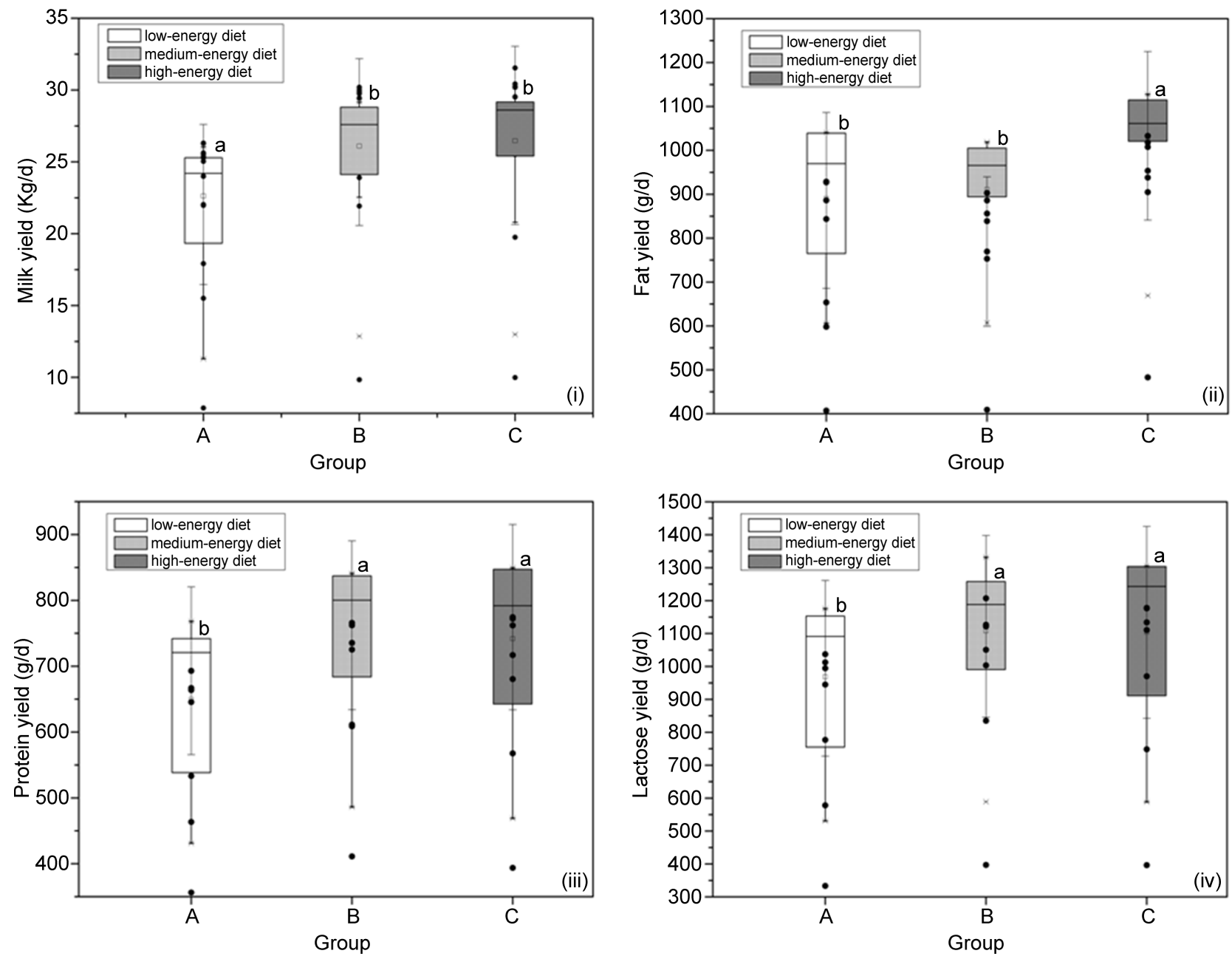

Figure 2. Effects of dietary energy density in the dry period on the milk yield production performance of dairy cows. (i) milk yield; (ii) fat yield; (iii) protein yield; (iv) lactose yield. For data on every box plot, different superscript letters indicate significant differences $(P<0.05)$, and the same superscript letters indicate no significant differences $(P>0.05) ; 0.05<P<0.1$ indicates a trend of difference; and $P>0.1$ indicates no significant difference.

protein, lactose, non-fat solids, or total solids $(P>0.05)$. Milk fat yield was significantly higher in group $\mathrm{C}$ than in groups $\mathrm{A}$ and $\mathrm{B}(P<0.05)$, and there was no difference between the latter two groups. Milk protein and lactose yields exhibited similar trends. Both parameters were highly significantly lower in group A than in groups $\mathrm{B}$ and $\mathrm{C}(P<0.01)$, with no difference between the latter two groups.

\subsection{Effects of DED in the Dry Period on BCS of Dairy Cows}

Table 4 and Figure 3 indicates that the prepartum BCS of dairy cows was highly significantly greater in groups $\mathrm{B}$ and $\mathrm{C}$ than in group $\mathrm{A}(P<0.01)$; there was no difference between the former two groups. Postpartum BCS in group A was highly significantly greater than those in groups B and $\mathrm{C}(P<0.01)$, with no difference between the latter two groups. Group A exhibited the lowest BCS during the prepartum period, which increased by 0.31 from the dry period to calving; the scores of groups B and C increased by 0.51 and 0.53 , respectively. Groups B and $\mathrm{C}$ exhibited large decreases in BCS during the postpartum period ( 0.87 and 
Table 4. Effects of dietary energy density in the dry period on the body condition score (BCS) of dairy cows.

\begin{tabular}{cccccc}
\hline Item & Group A & Group B & Group C & SEM & $P$-value \\
\hline BCS & & & & & \\
Prepartum & $3.40^{\mathrm{b}}$ & $3.51^{\mathrm{a}}$ & $3.54^{\mathrm{a}}$ & 0.06 & 0.0058 \\
Postpartum & $2.94^{\mathrm{a}}$ & $2.83^{\mathrm{b}}$ & $2.82^{\mathrm{b}}$ & 0.03 & $<0.0001$ \\
BCS change & & & & & \\
Prepartum & +0.31 & +0.51 & +0.53 & & \\
Postpartum & -0.52 & -0.69 & -0.87 & & \\
\hline
\end{tabular}

Note: Values are the means of three scores evaluated by three individuals. $P>0.1$ indicates no significant difference. Criteria for BCS evaluation (Ferguson, et al, 1994): 1 point: very thin; 2 points: thin; 3 points: normal (moderate nutrition); 4 points: obese; 5 points: very obese.

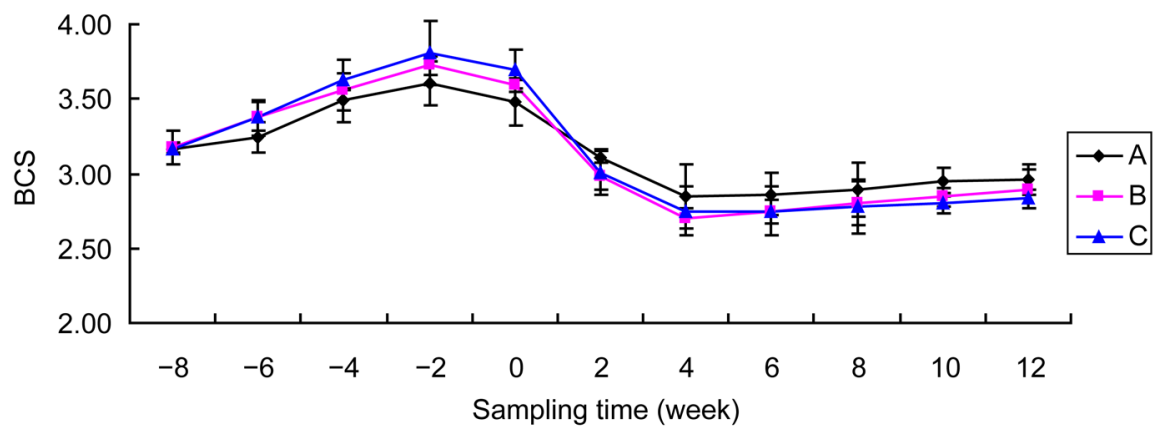

Figure 3. Effects of dietary energy density in the dry period on the body condition score (BCS) of dairy cows.

0.69 , respectively); group A exhibited a small decrease in BCS (0.52). Figure 3 demonstrates that in all groups, BCS exhibited an upward trend and peaked at approximately 2 weeks prepartum; thereafter, BCS rapidly decreased to trough levels at 4 weeks postpartum before leveling off. Although there was no statistically significant difference in postpartum BCS between groups B and C, the former group gradually improved relative to the latter group after 6 weeks postpartum.

\subsection{Effects of DED in the Dry Period on the Plasma Biochemistry of Dairy Cows}

GLU: Table 5 and Figure 4(i) demonstrate that the plasma GLU levels of dairy cows increased rapidly from 2 weeks prepartum and peaked at calving; thereafter, a rapid decline occurred, and GLU levels fell to trough levels at 1 week postpartum, followed by fluctuations at constant levels. There were no differences between the three groups in either the prepartum or postpartum period $(P>$ 0.05).

TG: Table 5 and Figure 4(ii) demonstrate that plasma TG levels of dairy cows remained higher prepartum than postpartum in all groups. TG levels increased from 8 weeks prepartum and peaked at 4 weeks prepartum; thereafter, the values declined to trough levels at 1 week postpartum and slightly increased with 
Table 5. Effects of dietary energy density in the dry period on plasma biochemistry of dairy cow.

\begin{tabular}{|c|c|c|c|c|c|}
\hline Item & Group A & Group B & Group C & SEM & $P$-value \\
\hline \multicolumn{6}{|l|}{ GLU (mmol/L) } \\
\hline Prepartum & 3.30 & 3.69 & 3.45 & 0.16 & 0.2229 \\
\hline Postpartum & 3.43 & 3.32 & 3.42 & 0.05 & 0.3697 \\
\hline \multicolumn{6}{|l|}{$\mathrm{TG}(\mathrm{mmol} / \mathrm{L})$} \\
\hline Prepartum & 0.42 & 0.47 & 0.46 & 0.02 & 0.1191 \\
\hline Postpartum & $0.39^{\mathrm{a}}$ & $0.35^{\mathrm{b}}$ & $0.36^{\mathrm{ab}}$ & 0.01 & 0.0559 \\
\hline \multicolumn{6}{|c|}{ BHBA $(\mu \mathrm{mol} / \mathrm{ml})$} \\
\hline Prepartum & 1.22 & 1.21 & 1.21 & 0.01 & 0.9198 \\
\hline Postpartum & $1.31^{\mathrm{b}}$ & $1.32^{\mathrm{b}}$ & $1.46^{\mathrm{a}}$ & 0.04 & 0.0071 \\
\hline \multicolumn{6}{|l|}{ NEFA $(\mu \mathrm{mol} / \mathrm{L})$} \\
\hline Prepartum & 446.45 & 449.04 & 404.77 & 45.35 & 0.3888 \\
\hline Postpartum & $475.24^{\mathrm{b}}$ & $566.73^{\mathrm{a}}$ & $596.27^{\mathrm{a}}$ & 58.21 & 0.0012 \\
\hline \multicolumn{6}{|c|}{ UREA (mmol/L) } \\
\hline Prepartum & 4.11 & 3.91 & 3.78 & 0.12 & 0.4596 \\
\hline Postpartum & $3.27^{\mathrm{b}}$ & $3.76^{\mathrm{a}}$ & $3.56^{\mathrm{ab}}$ & 0.13 & 0.1137 \\
\hline \multicolumn{6}{|l|}{$\operatorname{ALT}(\mathrm{U} / \mathrm{L})$} \\
\hline Prepartum & 14.80 & 16.20 & 15.00 & 0.89 & 0.3900 \\
\hline Postpartum & $19.14^{\mathrm{b}}$ & $24.29^{\mathrm{a}}$ & $23.43^{\mathrm{a}}$ & 1.66 & 0.0006 \\
\hline \multicolumn{6}{|l|}{ AST (U/L) } \\
\hline Prepartum & 50.80 & 52.40 & 51.40 & 1.73 & 0.4096 \\
\hline Postpartum & $61.29^{\mathrm{b}}$ & $70.29^{\mathrm{a}}$ & $71.86^{\mathrm{a}}$ & 1.47 & 0.0099 \\
\hline \multicolumn{6}{|l|}{ AST/ALT } \\
\hline Prepartum & 3.46 & 3.39 & 3.66 & 0.23 & 0.4499 \\
\hline Postpartum & 4.69 & 3.09 & 3.38 & 0.40 & 0.1640 \\
\hline \multicolumn{6}{|l|}{$\mathrm{TP}(\mathrm{g} / \mathrm{L})$} \\
\hline Prepartum & 66.16 & 68.64 & 69.76 & 1.18 & 0.1573 \\
\hline Postpartum & 74.94 & 71.64 & 74.40 & 0.99 & 0.2053 \\
\hline \multicolumn{6}{|l|}{$\operatorname{ALB}(\mathrm{g} / \mathrm{L})$} \\
\hline Prepartum & 32.26 & 31.48 & 31.48 & 0.23 & 0.2762 \\
\hline Postpartum & 30.31 & 31.39 & 31.26 & 0.32 & 0.2170 \\
\hline
\end{tabular}

Note: GLU, glucose; TG, triglyceride; BHBA, $\beta$-hydroxybutyrate; NEFA, non-esterified fatty acid; UREA, urea nitrogen; ALT, alanine aminotransferase; AST, aspartate aminotransferase; AST/ALT, aspartate aminotransferase/alanine aminotransferase; TP, total protein; ALB, albumin. 

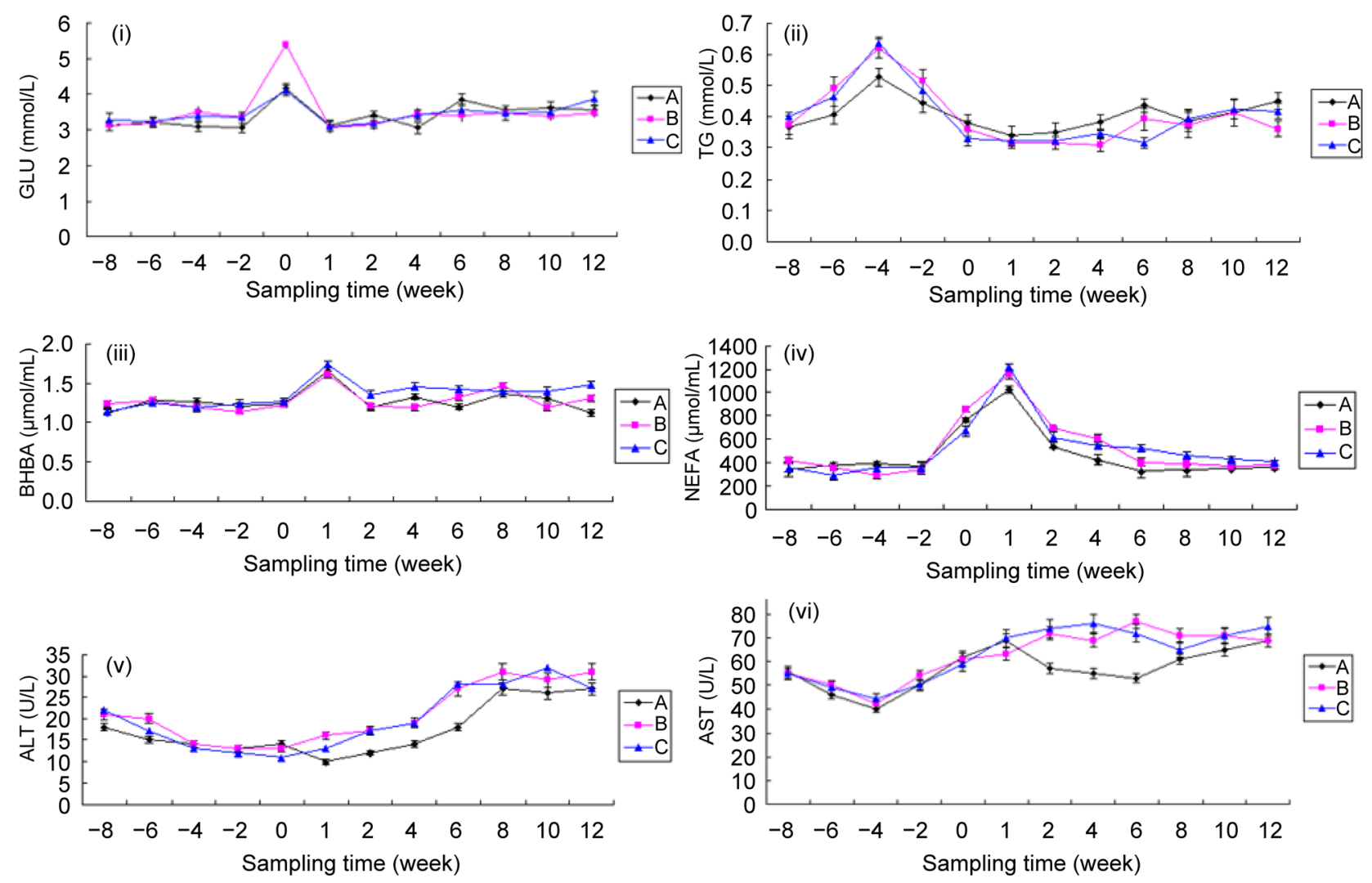

Figure 4. Effects of dietary energy density in the dry period on plasma biochemistry of dairy cows. (i) GLU, glucose; (ii) TG, triglyceride; (iii) BHBA, $\beta$-hydroxybutyrate; (iv) NEFA, non-esterified fatty acid; (v) ALT, alanine aminotransferase; (vi) AST, aspartate aminotransferase.

fluctuations. Prepartum and postpartum TG levels exhibited no differences among the groups $(P>0.05)$; however, there was a trend of difference between the groups postpartum $(0.05<P<0.1)$. Postpartum TG was significantly higher in group A than in group B; neither group exhibited differences relative to group C.

BHBA: Table 5 and Figure 4(iii) demonstrate that the plasma BHBA levels of dairy cows were higher postpartum than prepartum in all groups. There were no differences between the three groups prepartum $(P>0.05)$. However, group $\mathrm{C}$ was highly significantly greater than groups A and B postpartum $(P<0.01)$, with no difference between the latter two groups. In all groups of dairy cows, plasma BHBA began to increase from 2 weeks prepartum and peaked at 1 week prepartum. In the following week, BHBA decreased rapidly and then leveled off.

NEFA: Table 5 and Figure 4(iv) demonstrate that plasma NEFA levels of dairy cows were higher postpartum than prepartum in all groups. There were no differences between the groups prepartum $(P>0.05)$. However, group A was highly significantly lower than groups B and C postpartum $(P<0.01)$, with no difference between the latter two groups. NEFA levels remained stable from 8 weeks to 2 weeks prepartum and increased rapidly to peak levels at 1 week postpartum before rapidly decreasing and then leveling off in $6-12$ weeks postpartum. Group B was higher than group C for 2 - 4 weeks postpartum. The opposite trend was observed after 6 weeks postpartum, and group C dropped to trough 
levels at approximately 12 weeks postpartum before gradually leveling off.

ALT: Table 5 and Figure 4(v) illustrate that the plasma ALT levels of dairy cows were markedly lower prepartum than postpartum in all groups. The values initially decreased prepartum before increasing postpartum, peaked at 8 weeks postpartum, and then leveled off. Group A was highly significantly lower than groups $\mathrm{B}$ or $\mathrm{C}$ postpartum $(P<0.01)$; the latter two groups exhibited no differences between each other. There were no differences between the three groups prepartum.

AST: Table 5 and Figure 4(vi) demonstrate that there were no differences between the groups with respect to prepartum plasma AST levels $(P>0.05)$. Group A was highly significantly lower than groups B and C postpartum $(P<$ 0.01 ), with no difference between the latter two groups. AST levels exhibited a downward trend from 8 weeks prepartum and fell to trough levels at 4 weeks prepartum, followed by increases. Groups B and C peaked at 1 week postpartum and then gradually leveled off. Group A reached peak levels at 1 week postpartum and then decreased to trough levels at 6 weeks postpartum. Thereafter, group A increased again and returned to the same level as the other two groups at 12 weeks postpartum.

Table 5 demonstrates that the three groups exhibited no differences in plasma biochemistry with respect to UREA, AST/ALT, TP, or ALB, either prepartum or postpartum $(P>0.05)$. However, with regard to postpartum plasma UREA levels, group B was significantly higher than group A, and neither group was different compared with group C.

\subsection{Effects of DED in the Dry Period on the Plasma Hormone Levels of Dairy Cows}

INS: Figure 5(i) demonstrates that the plasma INS levels of dairy cows were generally stable in all groups during the early dry period. The values decreased towards calving and fell to trough levels at 1 week postpartum. Thereafter, the values slowly increased and then leveled off at approximately 12 weeks postpartum. Table 6 demonstrates that group A was highly significantly lower than groups B and C prepartum $(P<0.01)$, with no difference between the latter two groups. There was no difference between the three groups postpartum $(P>$ 0.05).

GN: Figure 5(ii) demonstrates that the plasma GN levels of dairy cows were higher postpartum than prepartum in all groups. GN levels initially increased prepartum and then decreased close to calving. The trough levels were observed at calving, with increases postpartum. The values gradually leveled off at approximately 4 weeks postpartum, and group $C$ returned to the same levels of groups A and B until 12 weeks postpartum. Table 6 shows that prepartum plasma GN levels exhibited highly significant differences between groups $(P<0.01)$; group $\mathrm{C}$ was higher than group $\mathrm{B}$, and the latter surpassed group $\mathrm{A}$. Group $\mathrm{C}$ was highly significantly greater than groups $A$ and B postpartum $(P<0.01)$, with no difference between the latter two groups. 

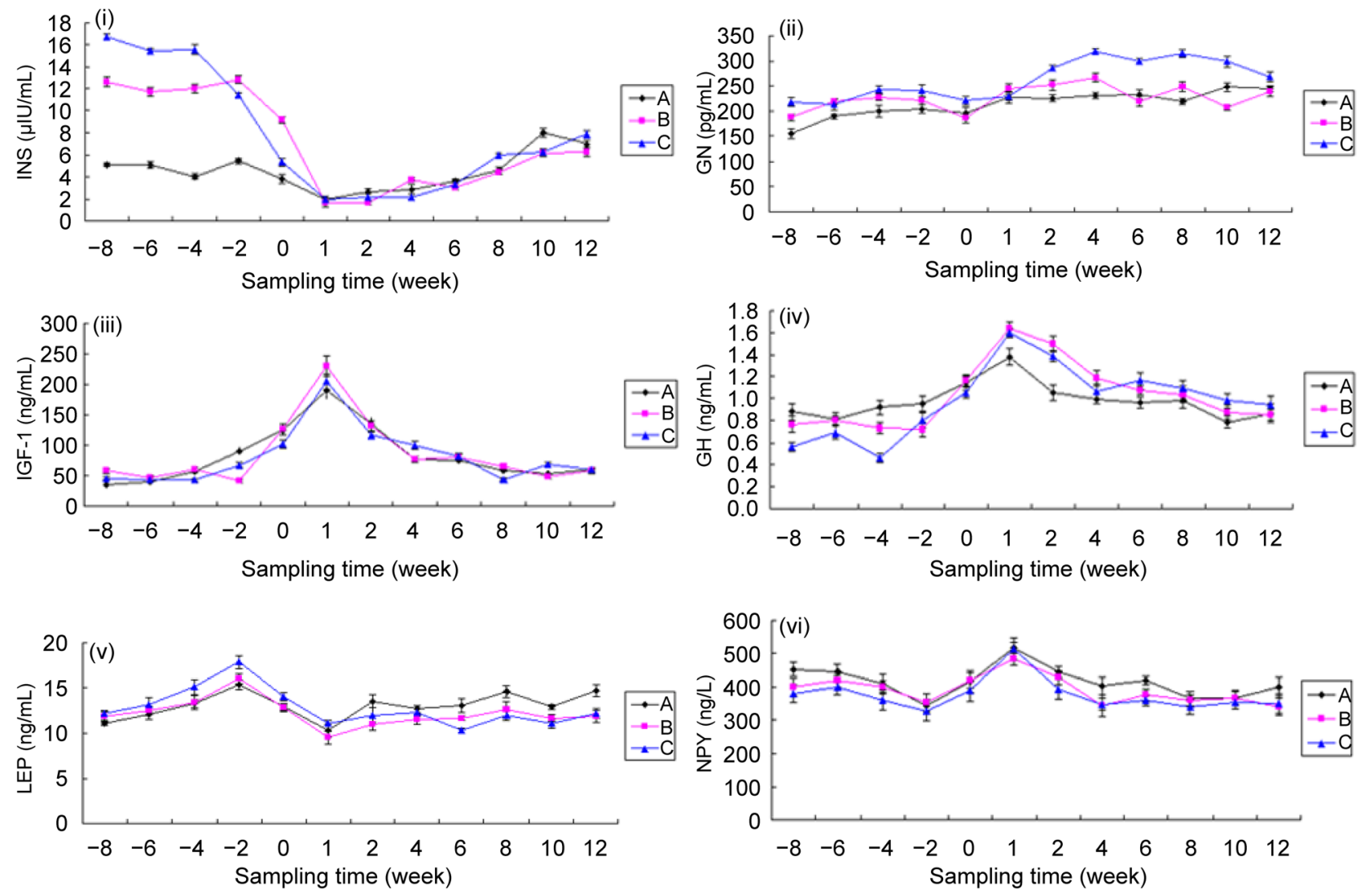

Figure 5. Effects of dietary energy density in the dry period on plasma hormne of dairy cows. (i) INS, insulin; (ii) GN, glucagon; (iii) IGF-1, insulin-like growth factor-1; (iv) GH, growth hormone; (v) LEP, leptin; (vi) NPY, neuropeptide.

Table 6. Effects of dietary energy density in the dry period on plasma hormone levels of dairy cows.

\begin{tabular}{|c|c|c|c|c|c|}
\hline Item & Group A & Group B & Group C & SEM & $P$-value \\
\hline \multicolumn{6}{|l|}{ INS $(\mu \mathrm{IU} / \mathrm{ml})$} \\
\hline Prepartum & $4.74^{\mathrm{b}}$ & $11.66^{\mathrm{a}}$ & $12.89^{\mathrm{a}}$ & 1.18 & 0.0012 \\
\hline Postpartum & 4.41 & 3.88 & 4.24 & 0.46 & 0.3650 \\
\hline \multicolumn{6}{|l|}{$\mathrm{GN}(\mathrm{pg} / \mathrm{ml})$} \\
\hline Prepartum & $188.42^{\mathrm{c}}$ & $207.81^{\mathrm{b}}$ & $226.44^{\mathrm{a}}$ & 5.97 & 0.0032 \\
\hline Postpartum & $232.11^{\mathrm{b}}$ & $239.00^{\mathrm{b}}$ & $287.78^{\mathrm{a}}$ & 7.20 & 0.0013 \\
\hline \multicolumn{6}{|l|}{ IGF-1 (ng/ml) } \\
\hline Prepartum & 69.40 & 66.32 & 60.40 & 7.84 & 0.6462 \\
\hline Postpartum & 92.55 & 98.62 & 96.12 & 11.60 & 0.6486 \\
\hline \multicolumn{6}{|l|}{$\mathrm{GH}(\mathrm{ng} / \mathrm{ml})$} \\
\hline Prepartum & $0.94^{\mathrm{a}}$ & $0.83^{\mathrm{ab}}$ & $0.72^{\mathrm{b}}$ & 0.05 & 0.0155 \\
\hline Postpartum & $1.00^{\mathrm{b}}$ & $1.16^{\mathrm{a}}$ & $1.17^{\mathrm{a}}$ & 0.05 & 0.0037 \\
\hline \multicolumn{6}{|l|}{$\operatorname{LEP}(\mathrm{ng} / \mathrm{ml})$} \\
\hline Prepartum & $12.93^{\mathrm{b}}$ & $13.31^{\mathrm{b}}$ & $14.46^{\mathrm{a}}$ & 0.47 & 0.0007 \\
\hline Postpartum & $13.09^{\mathrm{a}}$ & $11.37^{\mathrm{b}}$ & $11.50^{\mathrm{b}}$ & 0.29 & 0.0020 \\
\hline \multicolumn{6}{|l|}{ NPY (ng/L) } \\
\hline Prepartum & $412.98^{\mathrm{a}}$ & $397.00^{\mathrm{a}}$ & $369.95^{\mathrm{b}}$ & 9.46 & 0.0050 \\
\hline Postpartum & $416.68^{\mathrm{a}}$ & $385.08^{\mathrm{b}}$ & $378.72^{\mathrm{b}}$ & 12.17 & 0.0021 \\
\hline
\end{tabular}

Note: INS, insulin; GN, glucagon; IGF-1, insulin-like growth factor-1; GH, growth hormone; LEP, leptin; NPY, neuropeptide. 
IGF-1: Table 6 indicates that plasma IGF-1 levels increased towards calving and peaked at 1 week postpartum before decreasing which is shown in Figure 5(iii). There were no differences among the groups in the prepartum or postpartum periods $(P>0.05)$.

GH: Table 6 and Figure 5(iv) demonstrate that the plasma GH levels of dairy cows fluctuated in an upward trend prepartum and peaked at 1 week postpartum; thereafter, the values decreased and exhibited a stable trend at approximately 12 weeks postpartum. Group A was significantly higher than group C prepartum ( $P$ $<0.05$ ), and neither group exhibited differences relative to group B. Group A was highly significantly lower than groups B and $C$ postpartum $(P<0.01)$, with no difference between the latter two groups. Although the difference was not statistically significant, group B was lower than group C from 6 weeks postpartum.

LEP: Table 6 and Figure 5(v) demonstrate that the plasma LEP levels of dairy cows initially increased from 8 weeks prepartum and peaked at 2 weeks prepartum before falling to trough levels at 1 week postpartum. Subsequently, the values increased in all groups and remained stable with fluctuations. Group $\mathrm{C}$ was highly significantly greater than groups A and B prepartum $(P<0.01)$, with no difference between the latter two groups. Group A was highly significantly greater than groups $\mathrm{B}$ and $\mathrm{C}$ postpartum $(P<0.01)$, with no difference between the latter two groups.

NPY: Table 6 and Figure 5(vi) demonstrate that the plasma NPY levels of dairy cows initially decreased from 8 weeks prepartum and fell to trough levels at 2 weeks prepartum, before increasing to peak levels at 1 week postpartum. The values decreased in all groups from 1 week postpartum and then remained stable with fluctuations. Group C was highly significantly lower than groups A and B prepartum $(P<0.01)$, with no difference between the latter two groups. Group A was highly significantly greater than groups $\mathrm{B}$ and $\mathrm{C}$ postpartum $(P<0.01)$, and no difference was found between the latter two groups.

\section{Discussion}

\subsection{Effects of DED in the Dry Period on the Prepartum DMI of Dairy Cows}

In this study, the average daily DMI of dairy cows constantly decreased from 3 weeks prepartum to calving in all groups, and the relative decreases were $38 \%$ (group A), 24\% (group B), and 39\% (group C). DMI always decreases to varying degrees towards calving [2] [10] [11] [12]. The fetus rapidly grows in late pregnancy and can occupy the abdominal cavity and mechanically compress the rumen. As a consequence, the volume of the rumen becomes smaller and thus may limit the intake of DM. With regard to the average daily DMI of dairy cows prepartum, group A was lower than group B, whereas the latter was lower than group C. The average DMI values of the three groups were 11.96, 13.41, and $14.31 \mathrm{~kg}$, exhibiting highly significant differences among the groups $(P<0.01)$. This result may be related to the palatability of the diet. The high-energy diet had a higher concentrate: forage ratio and better palatability, which could sti- 
mulate the intake of DM by cows. Therefore, prepartum DMI was highest in the high-energy group and lowest in the low-energy group. The same result has been reported by Holcomb et al., who found that DMI was highly significantly increased in dairy cows fed a low-forage diet compared with those fed a highforage $\operatorname{diet}(P=0.007)$ [3].

\subsection{Effects of DED in the Dry Period on the MY and MC of Dairy Cows}

Milk yield is one of the important indicators of the production performance of dairy cows. Peripartum NEB often causes fat metabolism disorders in highyielding dairy cows, leading to peripartum conditions such as ketosis and fatty liver, seriously affecting MY. It has been recently reported that the level of prepartum nutrition has no effect on the postpartum MY of dairy cows. Dairy cows can maintain milk synthesis by tissue mobilization [13]. In the current study, the MY of dairy cows was highly significantly lower in group A than in groups $\mathrm{B}$ and C $(P<0.01)$, with no difference between the latter two groups; the decrease in group A was $14.5 \%$. Other studies have reported that low-energy diets from 28 days prepartum to calving helps improve postpartum MY [14] [15]. Additionally, Douglas et al. reported that prepartum feed restriction raised the MY of cows by $1.5-2.5 \mathrm{~kg} / \mathrm{d}$ compared with ad libitum feeding [6]. The opposite result was obtained in the current study, perhaps owing to different lengths of the trial period or different feeding patterns. The animal feeding trial was started from the dry period (56 days prepartum) in the present study, and only one diet formula was applied across the dry period.

The prepartum treatment did not affect the milk fat, protein, lactose, total solids, or non-fat solids of the dairy cows $(P>0.05)$. This finding is consistent with the result of Doeple, who reported that prepartum energy density has little effect on the postpartum MC of dairy cows [13]. The three groups of dairy cows exhibited significant differences in postpartum milk protein yield $(P<0.01)$, fat yield $(P<0.05)$, and lactose yield $(P<0.01)$. Such differences may be associated with the variations in MY. Because postpartum milk fat, protein, and lactose showed no differences among groups, the MY determined the yield of milk fat, protein and lactose. The significant differences in postpartum MY likely resulted in markedly different yields of milk fat, protein, and lactose.

\subsection{Effects of DED in the Dry Period on BCS of Dairy Cows}

The prepartum BCS of dairy cows exhibited an upward trend over time in all groups. Groups B and C were highly significantly elevated relative to group A ( $P$ $<0.01$ ), possibly related to DED and prepartum DMI. The average DMI values of groups $\mathrm{A}, \mathrm{B}$, and $\mathrm{C}$ were $11.96,13.41$, and $14.31 \mathrm{~kg}$, respectively, and the $\mathrm{NE}_{\mathrm{L}}$ exhibited the trend $\mathrm{A}<\mathrm{B}<\mathrm{C}$ (Table 3). From the perspective of energy balance, groups $B$ and $C$ ingested an excessive amount of energy and converted the energy to fat for storage, thus increasing BCS. Additionally, Agenäs et al. fed three groups of dairy cows with different amounts of DM as low-, medium-, and 
high-energy diets; the authors found that prepartum BCS was significantly lower in the low-energy group than in the other two groups $(P=0.05)$ [4]. Waltner et al. (1993) and Putnam and Varga (1998) posit that poor BCS at calving can reduce the MY of dairy cows during early lactation, consistent with the current results [16] [17].

With respect to postpartum BCS, group A was highly significantly elevated relative to groups $\mathrm{B}$ and $\mathrm{C}(P<0.01)$. There were marked decreases in the $\mathrm{BCS}$ of dairy cows in the latter two groups. However, a few studies have reported that prepartum factors such as DED and parity have no significant effects on the postpartum BCS of cows [18] [19] [20]. This finding is inconsistent with the current results. The changes in the BCS of dairy cows from prepartum to postpartum are primarily associated with calving-induced endocrine and metabolic changes (including fetal output, DMI decline, and lactation). Although groups B and $\mathrm{C}$ exhibited no statistically significant difference in postpartum BCS, the former group gradually improved relative to the latter group after 6 weeks postpartum. This phenomenon is believed to be associated with the prolonged NEB in dairy cows of group C. This point can be supported by the plasma NEFA levels measured in the current study, which revealed that the levels in group $\mathrm{C}$ were higher than those in group B from 6 to 12 weeks postpartum.

\subsection{Effects of DED in the Dry Period on the Plasma Biochemistry of Dairy Cows}

Changes in the GLU level reflect the dynamic equilibrium of glucose uptake, transport, and metabolism in the body. Circulating blood GLU levels reflect the level of energy metabolism in the body of dairy cows. Increased GLU facilitates INS secretion, whereas INS promotes glycogen/protein synthesis and fat deposition. Meanwhile, there exists negative feedback in the regulation of the body. When GLU levels are excessively low, INS secretion is inhibited and GN levels are elevated; this mechanism facilitates gluconeogenesis and glycogenolysis, increases GLU, and thereby maintains relatively constant GLU levels. Janovick et al. have reported that GLU levels are significantly higher in dairy cows fed with diets meeting $150 \%$ of their energy requirements compared with those fed diets meeting $100 \%$ or $80 \%$ of their energy requirements; there were no differences between the latter two groups [20]. Other studies reported that GLU levels are higher in dairy cows fed an ad libitum high-energy diet than in those under feed restriction [6] [7] [21]. This finding is observed primarily because a high-energy diet contains a higher level of starch, favoring the synthesis of propionic acids in the rumen, namely more gluconeogenic precursors. The current results indicate that the prepartum levels of GLU exhibited no significant differences among the three groups of dairy cows $(P>0.05)$. All groups of dairy cows may have experienced a positive energy balance prepartum, and the difference in DED was insufficient to affect GLU levels. Plasma GLU levels markedly increased in all groups close to the time of calving, and group B exhibited the highest GLU levels. The rapid GLU increase is believed to be related to decreasing plasma INS 
near the time of calving or may be the result of calving stress. Further study is required to analyze why plasma GLU was the highest in group B. Moreover, there were no significant differences in postpartum plasma GLU levels among the three groups of dairy cows $(P>0.05)$. This result may be associated with a serious state of postpartum NEB in all groups and postpartum regulation of GLU and INS.

Fat intake rarely induces elevations in the blood lipids of ruminants. Fat is transported in the form of fatty acid-binding ALB and stored as TG in the body [22]. Although the liver is an essential site for TG synthesis, the liver is unable store this product. If the liver fails to transport synthesized TG in a timely manner, it will form fatty liver. In the current study, prepartum plasma TG levels increased over time among all groups of dairy cows. This change is related to the synthesis of TG from the fat intake by the liver and subsequent transport into the blood by lipoproteins. There were marked decreases in plasma TG levels from 4 weeks prepartum, and trough levels were observed at 1 week postpartum. These changes may be related to decreased DMI and reduced fat intake at approximately 4 weeks prepartum. Meanwhile, fetal development and breast tissue repair may have substantially increased energy demand, leaving no extra energy supply to synthesize TG. Plasma TG levels were consistently higher in the prepartum period than in the postpartum period in all groups. A possible reason for this finding is that postpartum dairy cows began to lactate, and mammary cells consume a large amount of fatty acids to synthesize milk fat, whereas the levels of available fatty acids are reduced after TG synthesis by the liver [13]. The postpartum levels of TG exhibited a trend of difference $(0.05<P<0.1)$, and group A was significantly higher than group $\mathrm{B}$. These results may also be explained by the above mechanism. Because milk fat yield was relatively low in group A, the uptake and utilization of fatty acids by breast tissue would be reduced accordingly.

Elevations of blood NEFA levels are an important sign of NEB and body fat mobilization in dairy cows, and any causative factors of NEB can lead to an elevation in blood NEFA levels [23]. The majority of NEFA enters the liver, and if it is not completely oxidized, NEFA will generate large levels of BHBA, increasing the risk of cows suffering from ketosis. Under normal circumstances, blood NEFA and BHBA levels exhibit the same trends. In the present study, no differences were obtained in prepartum plasma NEFA or BHBA levels among the three groups. The DMI of dairy cows markedly decreased towards calving, whereas both plasma NEFA and BHBA levels substantially increased in all groups. Research has demonstrated that DED does not affect NEFA [5] [21] [24] or BHBA [6] [19] [20] levels in dairy cows in the early peripartum period. Taken together, the above findings suggest that prepartum low-energy feeding or restricted feeding may result in a NEB in dairy cows; however, this state is insufficient to affect NEFA and BHBA metabolism and thus does not cause differences in concentrations.

The current study demonstrates that postpartum plasma NEFA and BHBA 
levels remained higher in group $C$ than in group A. This result suggests that the high-energy group remained in a serious state of NEB postpartum, which would inevitably lead to fat mobilization. This mechanism explains the higher plasma NEFA and BHBA levels in the high-energy group. Similarly, other studies have reported that low-energy feeding or restricted feeding prepartum results in lower postpartum plasma NEFA levels in dairy cows [7] [20]. Although the difference in NEFA level was not statistically significant, the levels in group $\mathrm{C}$ were higher than those in group A from 6 weeks postpartum; the NEFA levels of group C decreased until reaching the lowest value at approximately 12 weeks postpartum and then leveled off. This trend is indicative of a serious and long-lasting NEB in the high-energy group. Likewise, the changes in the BCS of dairy cows prove that group B gradually improved relative to group C after 6 weeks postpartum. Although group B also experienced a serious NEB, the duration of the NEB was relatively short and thus allowed the cows to quickly recover.

In summary, high-energy intake prepartum aggravated the NEB and increased the incidence of postpartum metabolic diseases (ketosis and fatty liver). Feeding with a low-energy diet effectively reduced the NEB. Although a medium-energy diet also aggregated the NEB, its duration was relatively short, and the resultant postpartum MY was higher than that associated with the low-energy diet. Similar results have been reported by Dann et al. [7], who found that high-energy excessive feeding prepartum results in a serious postpartum NEB and relatively high blood NEFA and BHBA levels; the effects of prepartum treatment gradually disappear with prolonged lactation. Moreover, Agenäs et al. fed three groups of dairy cows with different amounts of DM (low-, medium-, and high-energy diets) throughout the dry period; the results revealed a serious postpartum NEB and more weight loss in the high-energy group [4]. Additionally, similar results that high energy or excessive feeding is unfavorable for the postpartum NEB. have reported [5] [6] [13] [15].

In this study, the plasma ALT and AST levels of dairy cows exhibited no obvious differences between the three groups prepartum $(P>0.05)$. However, group A was highly significantly lower than groups B and C postpartum $(P<$ 0.01). Prepartum plasma ALT levels gradually decreased towards calving and then increased postpartum. The peak levels of plasma ALT were observed at 1 week postpartum. This result indicates that rapid increase of lactation yield leads to different degrees of liver damage and thus elevated blood AST levels 1 week postpartum; the liver damage was more severe in the medium-energy and highenergy groups. The AST/ALT ratio of dairy cows increased prepartum and peaked at calving, followed by decreases postpartum; the values gradually leveled off at approximately 8 weeks postpartum. These results indicate that DED can affect postpartum ALT and AST levels; both parameters were relatively low in the low-energy group. Thus, low-energy feeding prepartum has a protective effect on the liver, and high-energy feeding prepartum can impair liver function.

Blood TP and ALB levels are indicators of metabolic liver function. In the case of liver disease, ALB synthesis and transport can be blocked, resulting in de- 
creased serum ALB levels. The current study revealed that plasma TP and ALB levels exhibited no differences between groups either prepartum or postpartum $(P>0.05)$. This result indicates that prepartum DED has no effects on TP and ALB levels. UREA can be used as an indicator of protein accumulation in the body; UREA levels reflect dietary protein balance in the animal and nitrogenous substances balance in tissue metabolism. When the body is in a state of NEB, body fat mobilization is increased, and body protein decomposition is accelerated to supply energy. The process of protein decomposition is associated with increased ammonia from amino acids and elevated UREA levels. In the current study, the plasma UREA levels of dairy cows exhibited no significant differences among the groups prepartum or postpartum $(P>0.05)$; however, postpartum UREA was lowest in the low-energy group. This result indicates that the lowenergy group obtained relatively abundant energy postpartum and thus reduced the postpartum NEB.

\subsection{Effects of DED in the Dry Period on Blood Hormones of Dairy Cows}

Insulin can promote glycogen synthesis in the liver and fat synthesis in peripheral tissues, thereby increasing the cellular uptake and utilization of glucose and reducing GLU levels. High intake of high-energy diets by dairy cows increases the gastrointestinal intake of gluconeogenic precursors and thus improves the glucose uptake rate of the liver [25]. The increase of gluconeogenic precursors promotes the elevation of INS levels to maintain normal levels of GLU. The current results indicate that prepartum feeding of medium-energy or high-energy diets resulted in significantly higher plasma INS levels of dairy cows compared with the low-energy group $(P<0.01)$. Likewise, other studies have indicated that high-energy diets can improve plasma INS levels of dairy cows in the early peripartum period [5] [6] [7] [26]. The current study revealed that the plasma INS levels of dairy cows declined towards calving and fell to trough levels at 1 week postpartum. There were no differences among the three groups postpartum $(P>0.05)$. Peripartum cows may experience a serious NEB, wherein INS reduction indirectly facilitates the decomposition of body fat tissue; this finding is supported by the elevations in postpartum GN and GH levels.

IGF-1 is a peptide related to INS and regulated by GH, INS, nutrition, and sex hormones. IGF-1 and INS exert synergistic effects in regulating glucose metabolism and reducing GLU levels. The current study demonstrates that plasma IGF-1 levels of dairy cows increased towards calving and peaked at 1 week postpartum, followed by decreases. The variations in IGF-1 levels may be related to the changes in INS metabolism. Further, plasma INS levels decreased within 2 weeks postpartum. To control GLU levels, plasma IGF-1 was upregulated to reduce GLU. Postpartum plasma INS levels slowly rebounded and thus enhanced the regulation of GLU, whereas the IGF-1 levels declined. There were no differences in plasma IGF-1 levels among the groups in the prepartum or postpartum periods $(P>0.05)$, indicating that variations in prepartum energy intake have no 
effect on IGF-1.

Glucagon can promote the decomposition of hepatic glycogen and increase the levels of gluconeogenic precursors in dairy cows to elevate GLU levels [27]. The current results suggest that postpartum plasma GN levels consistently increased in all groups, and the high-energy group was highly significantly greater than the low-energy and medium-energy groups $(P<0.01)$. Moreover, the high-energy group maintained relatively high GN levels postpartum. The above results indicate that all groups of dairy cows experienced a NEB postpartum. Among the three groups, body fat mobilization was more serious and NEB lasted a longer period in the high-energy group. This point is also illustrated by the high yield of milk fat and significant decline in body condition in the highenergy group. Prepartum plasma GN levels exhibited highly significant differences among the three groups of dairy cows $(P<0.01)$; the high-energy group was higher than the medium-energy group, whereas the latter was less than the low-energy group. High prepartum plasma INS levels in dairy cows might result in increased GN in the high-energy group to ensure relatively constant GLU levels.

Growth hormone can facilitate glucose uptake, carbohydrate and fat decomposition, and nucleic acid and protein synthesis, mainly by participating in the regulation of metabolic processes. The current results indicate that prepartum feeding of low-energy diets can markedly elevate prepartum blood GH levels and promote body fat mobilization, and this point is supported by the low prepartum BCS of dairy cows in the low-energy group. However, there were also have the opposite result. stimulated ovariectomized ewes by administering either a full diet or restricted diet, and GH secretion decreased in the restricted group. The discrepant results may be due to different animal species and physiological states. Plasma GH peaked at 1 week postpartum, when the NEB and body fat mobilization were most severe. The low-energy group exhibited relatively low plasma GH levels postpartum and exhibited highly significant differences compared with the high-energy and medium-energy groups $(P<0.01)$. This result indicates that body fat mobilization was relatively weak in the low-energy group and that a low-energy diet was favorable for reducing postpartum NEB. The medium-energy group exhibited higher plasma GH levels than the high-energy group at 4 weeks prepartum, which may be related to the high MY in the medium-energy group, thereby resulting in a higher energy demand and serious mobilization of body fat. However, the high-energy group became higher than the medium-energy group at 6 weeks postpartum, indicating that the postpartum NEB lasted longer in the high-energy group than in the medium-energy group. The changes in plasma NEFA and BHBA levels also indicate that dairy cows in the high-energy group remained in a state of body fat mobilization. This is consistent with the result reported by Vandehaar that the NEB increases GH levels in the blood [18].

Leptin plays a pivotal role in regulating food intake, fat metabolism, and the reproductive and immune systems [28] [29]. The overall level of LEP is higher in 
obese individuals for both ruminants and monogastric animals [30]. In the current study, the high-energy group exhibited relatively high BCS prepartum, with highly significantly elevated LEP levels relative to the low-energy and mediumenergy groups $(P<0.01)$. Postpartum plasma LEP levels were reduced, and LEP reduction is related to the postpartum NEB [31]. We observed that the lowenergy group exhibited significantly higher postpartum plasma LEP levels than the medium-energy and low-energy groups $(P<0.01)$; however, prepartum feeding of the high-energy diet resulted in relatively low postpartum plasma LEP levels, and the cows remained in a serious NEB. This finding is consistent with the result reported by Liefers et al. that plasma LEP levels are relatively low in dairy cows with a NEB during lactation [32]. It has been reported that human placenta can produce LEP; once the placenta is discharged during calving, plasma LEP levels are reduced [29]. The current results indicate that plasma LEP levels of dairy cows decreased towards calving and fell to trough levels at 1 week postpartum. This downward trend of plasma LEP may be related to the discharge of placenta during calving.

Neuropeptide, which can improve appetite and DMI, is a powerful inducing factor to stimulate feed intake of animals. Similar NPY injection trials have been performed on animals in foreign countries over recent years, including rats , mice, sheep [33], and swine [34]. The results reveal that NPY can induce appetite and feed intake in animals, and a dose relationship has been demonstrated between NPY and feed intake within a certain range. On the basis of controlling feed intake, NPY can increase gluconeogenic precursors to facilitate gluconeogenesis and thereby increase glycogen accumulation to affect the body's energy balance. In the current study, the high-energy group exhibited significantly lower prepartum plasma NPY levels than the medium-energy or low-energy groups $(P<0.01)$. The low-energy group exhibited the highest plasma NPY levels, possibly because prepartum low-energy feeding resulted in a fasting and hunger state of the dairy cows, which could stimulate NPY secretion. Yang et al. also demonstrated that in a hunger state, NPY neurons are excited and NPY mRNA expression levels are elevated in the brain center [35]. Additionally, LEP has been reported to control food intake by regulating NPY synthesis and release. Elevation in LEP levels inhibit NPY mRNA expression and reduce NPY levels, thereby reducing feed intake of animals; thus, low prepartum plasma NPY levels in the high-energy group may be attributed to LEP regulation. With regard to postpartum plasma NPY levels, the low-energy group was highly significantly elevated relative to the medium-energy and high-energy groups $(P<0.01)$. This result indicates that prepartum low-energy feeding can improve postpartum DMI, promote gluconeogenesis, and increase fat and glycogen accumulation, effectively reducing the NEB. In contrast, prepartum high-energy feeding resulted in low feed intake and severe NEB in dairy cows postpartum.

\section{Conclusions}

Medium-energy and high-energy feeding in the dry period increased the post- 
partum milk yield of dairy cows. However, low-energy feeding reduced lactation performance, and there was a $14.5 \%$ reduction in the milk yield of the lowenergy group. Low-energy feeding in the dry period significantly reduced postpartum blood BHBA and NEFA levels, attenuated body fat mobilization, and mitigated the decline in postpartum body condition; thus, low-energy feeding can effectively reduce postpartum NEB. In contrast, high-energy feeding resulted in higher blood BHBA and NEFA levels, more serious postpartum NEB, and a serious decline in the postpartum BCS of dairy cows; thus, high-energy feeding may increase the incidence of postpartum disorders of energy metabolism such as ketosis and fatty liver in the dry period.

High-energy feeding in the dry period resulted in higher postpartum plasma AST and ALT activity in dairy cows relative to the medium-energy and lowenergy groups. This result indicates that high-energy feeding in the dry period can increase the postpartum burden on the liver and is more likely to cause liver dysfunction. Meanwhile, high-energy feeding increased blood GH and GN levels, indicating serious body fat mobilization and NEB in the high-energy group postpartum. Low-energy feeding in the dry period resulted in higher postpartum blood LEP and NPY levels of dairy cows compared with the medium-energy and high-energy groups.

\section{Acknowledgements}

The study was financially supported by the earmarked fund for Modern Agroindustry Technology Research System of China (CARS-37), Cattle Agro-industry Technology Research System of Shandong Province (SDAIT-12-011-06), natural science fund of China (31572427) (31372340) and cattle breed project of Shandong province. The author gratefully thanks the staff of aote Dairy Farm, Qingdao, China.

\section{References}

[1] Janovick, N.A. and Drackley, J.K. (2010) Prepartum Dietary Management of Energy Intake Affects Postpartum Intake and Lactation Performance by Primiparous and Multiparous Holstein Cows. Journal of Dairy Science, 93, 3086-3102. https://doi.org/10.3168/jds.2009-2656

[2] Grummer, R.R. (1995) Impact of Changes in Organic Nutrient Metabolism on Feeding the Transition Dairy Cow. Journal of Animal Science, 73, 2820-2833. https://doi.org/10.2527/1995.7392820x

[3] Holcomb, C.S., Van Horn, H.H., Head, H.H., et al. (2001) Effects of Prepartum Dry Matter Intake and Forage Percentage on Postpartum Performance of Lactating Dairy Cows. Journal of Dairy Science, 84, 2051-2058. https://doi.org/10.3168/jds.S0022-0302(01)74649-8

[4] Agenäs, S., Burstedt, E. and Holtenius, K. (2003) Effects of Feeding Intensity during the Dry Period. 1. Feed Intake, Body Weight, and Milk Production. Journal of Dairy Science, 86, 870-882. https://doi.org/10.3168/jds.S0022-0302(03)73670-4

[5] Holtenius, K., Agenäs, S., Delavaud, C. and Chilliard, Y. (2003) Effects of Feeding Intensity during the Dry Period. 2. Metabolic and Hormonal Responses. Journal of Dairy Science, 86, 883-891. https://doi.org/10.3168/jds.S0022-0302(03)73671-6 
[6] Douglas, G.N., Overton, T.R., Bateman, H.G., Dann, H.M. and Drackley, J.K. (2006) Prepartal Plane of Nutrition, Regardless of Dietary Energy Source, Affects Periparturient Metabolism and Dry Matter Intake in Holstein Cows. Journal of Dairy Science, 89, 2141-2157. https://doi.org/10.3168/jds.S0022-0302(06)72285-8

[7] Dann, H.M., Litherland, N.B., Underwood, J.P., et al. (2006) Diets during Far-Off and Close-Up Dry Periods Affect Periparturient Metabolism and Lactation in Multiparous Cows. Journal of Dairy Science, 89, 3563-3577. https://doi.org/10.3168/jds.S0022-0302(06)72396-7

[8] Beever, D.E. (2006) The Impact of Controlled Nutrition during the Dry Period on Dairy Cow Health, Fertility and Performance. Animal Reproduction Science, 96, 212-226.

[9] Ferguson, J.D., Galligan, D.T. and Thomsen, N. (1994) Principal Descriptors of Body Condition Score in Holstein Cows. Journal of Dairy Science, 77, 2695-2703. https://doi.org/10.3168/jds.S0022-0302(94)77212-X

[10] Dann, H.M., Varga, G.A. and Putnam, D.E. (1999) Improving Energy Supply to Late Gestation and Early Postpartum Dairy Cows. Journal of Dairy Science, 82, 1765-1778. https://doi.org/10.3168/jds.S0022-0302(99)75407-X

[11] Ingvartsen, K.L. and Andersen, J.B. (2000) Integration of Metabolism and Intake Regulation: A Review Focusing on Periparturient Animals. Journal of Dairy Science, 83, 1573-1597. https://doi.org/10.3168/jds.S0022-0302(00)75029-6

[12] Dewhurst, R.J., Moorby, J.M., Dhanoa, M.S., et al. (2000) Effects of Altering Energy and Protein Supply to Dairy Cows during the Dry Period. 1. Intake, Body Condition, and Milk Production. Journal of Dairy Science, 83, 1782-1794.

https://doi.org/10.3168/jds.S0022-0302(00)75049-1

[13] Doepel, L., Lapierre, H. and Kennelly, J.J. (2002) Peripartum Performance and Metabolism of Dairy Cows in Response to Prepartum Energy and Protein Intake. Journal of Dairy Science, 85, 2315-2334. https://doi.org/10.3168/jds.S0022-0302(02)74312-9

[14] Zuo, Z.C., Deng, J.L., Wang, Z., et al. (2005) Effects of Different Energy Intake on the Performance and Lipid Metabolism of Periparturient Dairy Cows. Heilongjiang Animal Science and Veterinary Medicine, 11, 19-22.

[15] Niu, S.L., Li, Y.F., Wang, Z., et al. (2005) Effects of Energy Intake on Plasma Concentration of Leptin and Milk Production of Leptin and Milk Production in Periparturient Dairy Cows. Animal Husbandry \& Veterinary Medicine, 37, 1-4.

[16] Waltner, S.S., McNamara, J.P. and Hillers, J.K. (1993) Relationships of Body Condition Score to Production Variables in High Producing Holstein Dairy Cattle. Journal of Dairy Science, 76, 3410-3419. https://doi.org/10.3168/jds.S0022-0302(93)77679-1

[17] Putnam, D.E. and Varga, G.A. (1998) Protein Density and Its Influence on Metabolite Concentration and Nitrogen Retention by Holstein Cows in Late Gestation. Journal of Dairy Science, 81, 1608-1618. https://doi.org/10.3168/jds.S0022-0302(98)75727-3

[18] Vandehaar, M.J., Yousif, G., Sharma, B.K., et al. (1999) Effect of Energy and Protein Density of Prepartum Diets on Fat and Protein Metabolism of Dairy Cattle in the Periparturient Period. Journal of Dairy Science, 82, 1282-1295. https://doi.org/10.3168/jds.S0022-0302(99)75351-8

[19] Rabelo, E., Rezende, R.L., Bertics, S.J., et al. (2003) Effects of Transition Diets Varying in Dietary Energy Density on Lactation Performance and Ruminal Parameters of Dairy Cows. Journal of Dairy Science, 86, 916-925. https://doi.org/10.3168/jds.S0022-0302(03)73674-1 
[20] Janovick, N.A., Boisclair, Y.R. and Drackley, J.K. (2011) Prepartum Dietary Energy Intake Affects Metabolism and Health during the Periparturient Period in Primiparous and Multiparous Holstein Cows. Journal of Dairy Science, 94, 1385-1400. https://doi.org/10.3168/jds.2010-3303

[21] Guo, J., Peters, R.R. and Kohn, R.A. (2007) Effect of a Transition Diet on Production Performance and Metabolism in Periparturient Dairy Cows. Journal of Dairy Science, 90, 5247-5258. https://doi.org/10.3168/jds.2007-0326

[22] Itoh, H., Tamura, K., Motoi, Y. and Kawawa, F. (1997) Serum Apolipoprotein B-100 Concentrations in Healthy and Diseased Cattle. Journal of Veterinary Medical Science, 59, 587-591. https://doi.org/10.1292/jvms.59.587

[23] Canfield, R.W., Sniffen, C.J. and Butler, W.R. (1990) Effects of Excess Degradable Protein on Postpartum Reproduction and Energy Balance in Dairy Cattle. Journal of Dairy Science, 73, 2342-2349. https://doi.org/10.3168/jds.S0022-0302(90)78916-3

[24] Rukkwamsuk, T., Kruip, T.A.M., Meijer, G.A.L. and Wensing, T. (1999) Hepatic Fatty Acid Composition in Periparturient Dairy Cows with Fatty Liver Induced by Intake of a High Energy Diet in the Dry Period. Journal of Dairy Science, 82, 280287. https://doi.org/10.3168/jds.S0022-0302(99)75234-3

[25] Rukkwamsuk, T., Wensing, T. and Geelen, M.J.H. (1998) Effect of Overfeeding during the Dry Period on Regulation of Adipose Tissue Metabolism in Dairy Cows during the Periparturient Period. Journal of Dairy Science, 81, 2904-2911. https://doi.org/10.3168/jds.S0022-0302(98)75851-5

[26] Rabelo, E., Rezende, R.L., Bertics, S.J., et al. (2005) Effects of Pre- and Post-Fresh Transition Diets Varying in Dietary Energy Density on Metabolic Status of Periparturient Dairy Cows. Journal of Dairy Science, 88, 4375-4383. https://doi.org/10.3168/jds.S0022-0302(05)73124-6

[27] Contreras, L.L., Ryan, C.M. and Overton, T.R. (2004) Effects of Dry Cow Grouping Strategy and Prepartum Body Condition Score on Performance and Health of Transition Dairy Cows. Journal of Dairy Science, 87, 517-523. https://doi.org/10.3168/jds.S0022-0302(04)73191-4

[28] Houseknecht, K.L. and Portocarrero, C.P. (1998) Leptin and Its Receptors: Regulators of Whole-Body Energy Homeostasis. Domestic Animal Endocrinology, 15, 457-475.

[29] Chilliard, Y., Bonnet, M., Delavaud, C., et al. (2001) Leptin in Ruminants. Gene Expression in Adipose Tissue and Mammary Gland, and Regulation of Plasma Concentration. Domestic Animal Endocrinology, 21, 271-295.

[30] Maffei, M., Halaas, J. and Ravussin, E. (1995) Leptin Levels in Human and Rodent: Measurement of Plasma Leptin and OB RNA in Obese and Weight-Reduced Subjects. Nature Medicine, 1, 1155-1161. https://doi.org/10.1038/nm1195-1155

[31] Block, S.S., Butler, W.R., Ehrhardt, R.A., Bell, A.W., Van Amburgh, M.E. and Boisclair, Y.R. (2001) Decreased Concentration of Plasma Leptin in Periparturient Dairy Cows Is Caused by Negative Energy Balance. Journal of Endocrinology, 171, 339-348. https://doi.org/10.1677/joe.0.1710339

[32] Liefers, S.C., Veerkamp, R.F., Te Pas, M.F.W., Delavaud, C., Chilliard, Y. and van der Lende, T. (2003) Leptin Concentrations in Relation to Energy Balance, Milk Yield, Intake, Live Weight, and Estrus in Dairy Cows. Journal of Dairy Science, 86, 799-807. https://doi.org/10.3168/jds.S0022-0302(03)73662-5

[33] Clark, J.T., Gist, R.S., Kalra, S.P. and Kalra, P.S. (1988) Alpha 2-Adrenoceptor Blockade Attenuates Feeding Behavior Induced by Neuropeptide Y and Epinephrine. Physiology \& Behavior, 43, 417-422. 
[34] Kalra, S.P., Dube, M.G., Sahu, A., Phelps, C.P. and Kalra, P.S. (1991) Neuropeptide Y Secretion Increases in the Paraventricular Nucleus in Association with Increased Appetite for Food. Proceedings of the National Academy of Sciences, 88, 1093110935. https://doi.org/10.1073/pnas.88.23.10931

[35] Yang, C., Cui, H.X., Fan, P., et al. (2005) Hypothalamus NPY Neuron Culture and Effects of Leptin on NPY mRNA in Rat. Basic Medical Sciences and Clinics, 25, 248-252.

Submit or recommend next manuscript to SCIRP and we will provide best service for you:

Accepting pre-submission inquiries through Email, Facebook, LinkedIn, Twitter, etc. A wide selection of journals (inclusive of 9 subjects, more than 200 journals) Providing 24-hour high-quality service User-friendly online submission system Fair and swift peer-review system Efficient typesetting and proofreading procedure Display of the result of downloads and visits, as well as the number of cited articles Maximum dissemination of your research work

Submit your manuscript at: http://papersubmission.scirp.org/ Or contactabb@scirp.org 